OPEN ACCESS

Edited by:

Daniel Petrovič,

University of Ljubljana, Slovenia

Reviewed by:

Shinichi Okuda,

Yamaguchi Prefectural Grand Medical

Center, Japan

Balint Lakatos,

Semmelweis University, Hungary

${ }^{*}$ Correspondence:

Patryk Leczyck patryk.leczycki@pm.me

Specialty section

This article was submitted to Heart Failure and Transplantation, a section of the journal Frontiers in Cardiovascular Medicine

Received: 09 April 2021

Accepted: 31 January 2022

Published: 24 February 2022

Citation:

Leczycki P, Banach M, Maciejewski M and Bielecka-Dabrowa A (2022) Heart

Failure Risk Predictions and Prognostic Factors in Adults With

Congenital Heart Diseases.

Front. Cardiovasc. Med. 9:692815.

doi: 10.3389/fcvm.2022.692815

\section{Heart Failure Risk Predictions and Prognostic Factors in Adults With Congenital Heart Diseases}

\author{
Patryk Leczycki ${ }^{1 *}$, Maciej Banach ${ }^{1,2}$, Marek Maciejewski ${ }^{1}$ and Agata Bielecka-Dabrowa ${ }^{1,2}$ \\ ${ }^{1}$ Department of Cardiology and Congenital Diseases of Adults, Polish Mother's Memorial Hospital Research Institute, Łodź, \\ Poland, ${ }^{2}$ Department of Preventive Cardiology and Lipidology, Medical University of Lodz, Łodź, Poland
}

In recent decades the number of adults with congenital heart diseases (ACHD) has increased significantly. This entails the need for scrupulous evaluation of the current condition of these patients. The ACHD population is one of the most challenging in contemporary medicine, especially as well-known scales such as the NYHA classification have very limited application. At the moment, there is a lack of universal parameters or scales on the basis of which we can easily capture the moment of deterioration of our ACHD patients' condition. Hence it is crucial to identify factors that are widely available, cheap and easy to use. There are studies showing more and more potential prognostic factors that may be of use in clinical practice: thorough assessment with echocardiography and magnetic resonance imaging (e.g., anatomy, ventricular function, longitudinal strain, shunt lesions, valvular defects, pericardial effusion, and pulmonary hypertension), cardiopulmonary exercise testing (e.g., peak oxygen uptake, ventilatory efficiency, chronotropic incompetence, and saturation) and biomarkers (e.g., N-terminal pro-brain type natriuretic peptide, growth-differentiation factor 15, high-sensitivity troponin $\mathrm{T}$, red cell distribution width, galectin-3, angiopoietin-2, asymmetrical dimethylarginine, and high-sensitivity C-reactive protein). Some of them are very promising, but more research is needed to create a specific panel on the basis of which we will be able to assess patients with specific congenital heart diseases.

Keywords: prognostic factor, adults with congenital heart disease (ACHD), congenital heart defect (CHD), risk prediction, heart failure, congenital heart disease

\section{INTRODUCTION}

In recent decades the number of adults with congenital heart diseases (ACHD) has increased significantly, mostly due to substantial progress in pediatric cardiac surgery and cardiology (1). Accurate prevalence of ACHD is not known and difficult to estimate. Nevertheless, the prevalence of ACHD is rapidly growing, exceeding the prevalence of congenital heart defects in the pediatric population two-fold (1).

More and more adult patients with CHD present advanced forms of heart failure (about 20$50 \%$ of this population) which is main cause of death in ACHD population, and their quantity will be growing (2-4). Patients at high risk of developing heart failure require systematic followup and diagnostic screening. The knowledge we have about diagnosis and treatment of HF has very limited usage in ACHD. First of all, unlike in the general population, adults with CHD form a very heterogenous population what impedes the creation of uniform standards of 
treatment. Prevalence of signs and symptoms of HF seems to be the highest in patients with functionally univentricular hearts post-Fontan palliation (40\%), in congenitally corrected TGA patients (32\%) and in patients with complete TGA (22\%) (5). The pathophysiology of HF in ACHD, unlike in the general population, is much more complex. It includes multiple causes: ventricular dysfunction caused by pressure/volume overload and compromised systolic ventricular function due to incorrect myocardial architecture, myocardial injuries during numerous surgeries and invasive interventions, ischemic heart disease that is based on congenital coronary arteries anomalies and arrhythmias (6). Secondly, there is very slow progress in the management of HF in CHDs, and many modern therapies has no proven benefits in this group of patients. Thirdly, we do not have an universal tool with which we can easily determine the severity of impaired physical functionality in ACHD (functional class) - the NYHA classification has limited usage due to overall tolerance of limited functionality in patients with CHDs. CHD present from birth, and patients adapt daily activities to their ability, thus, underestimating and under-reporting the severity of physical limitation (7).

The purpose of this work is to review current prognostic factors in ACHD and their significance in the diagnosis of heart failure, prognosis and management of patients with $\mathrm{CHD}$ and accompanying HF.

\section{MATERIALS AND METHODS}

We searched the electronic database PUBMED (2000-2021). Additionally, data from international cardiovascular meetings and guidelines of cardiovascular societies were searched. The main data search terms were: adult congenital heart disease, echocardiography, magnetic resonance imaging, exercise, cardiopulmonary exercise testing, biomarker(s), marker(s), heart failure, NYHA class, prognosis, risk factor(s).

\section{Prognostic Factors in Patients With CHD Transthoracic Echocardiography in Assessment of Prognostic Factors in ACHD}

The most basic parameter obtained in TTE is the systolic ventricular function (as expressed by an ejection fraction with the biplane Simpson's method), which is a well-established prognostic factor. Koyak et al. showed that moderately to severely impaired systemic ventricular function and moderate to severe subpulmonary ventricular dysfunction are predictors for sudden cardiac death (SCD) in the general CHD population (8). In adults with repaired tetralogy of Fallot, the link between moderate or severe left ventricular systolic dysfunction and very wide QRS complex ( $\geq 180 \mathrm{~ms}$ ) had positive $(66 \%)$ and negative $(93 \%)$ predictive value for SCD (9). Baggen et al. reported that size and function of the left atrium (left atrial volume index $\geq 34$ $\mathrm{mL} / \mathrm{m}^{2}$, total and active emptying fraction but especially length) were significantly associated with cardiovascular events (10). The authors concluded also that a normally sized left atrium could accurately rule out the risk of death and heart failure with a high negative predictive value (10). Also, it was reported that left ventricular longitudinal dysfunction assessed with strain was associated with SCD and life-threatening arrhythmias (11) and tricuspid or pulmonary valve regurgitation was a prognosticator of death (12). In post-fontan procedure patients the systolic to diastolic duration ratio has been described as one of the mortality predictors (systolic duration was measured from the onset to the end of AV valve regurgitation; diastolic duration was measured from the end of $\mathrm{AV}$ valve regurgitation to the onset of the subsequent AV valve regurgitation signal) (13). Additionally, in patients with a systemic right ventricle it seems that longitudinal systolic strain is related to elevated NT-proBNP, progression in New York Heart Association class, relevant arrhythmia and death $(14,15)$. In the Eisenmenger population tricuspid annular plane systolic excursion (TAPSE $<15 \mathrm{~mm}$ ) and ratio of right ventricular effective systolic to diastolic duration $(\geq 1.5$; systolic duration was measured from the onset to the end of tricuspid regurgitation and diastolic duration from the end of tricuspid regurgitation to the onset of the subsequent tricuspid regurgitation signal) have been of predictive value $(16,17)$. Moceri et al. proposed echocardiographic score based on the strongest echocardiographic predictors of outcome, including 1 point for each of the following: tricuspid annular plane systolic excursion $<15 \mathrm{~mm}$, ratio of right ventricular effective systolic to diastolic duration $\geq 1.5$, RA area $\geq 25 \mathrm{~cm}^{2}$, ratio of RA to left atrial area $\geq 1.5$, that was highly predictive of mortality (16). Therefore, one may consider to incorporate it routinely in the assessment of Eisenmenger patients. Abnormal right atrial area $\left(\geq 25 \mathrm{~cm}^{2}\right)$ and ratio of right atrial to left atrial area $(\geq 1.5)$ have also been reported as a bad prognostic factors in patients with Eisenmenger syndrome and pulmonary hypertension $(16,17)$. Additionally, pericardial effusion or pretricuspid shunt were reported to be a prognosticator of death (18).

\section{Magnetic Resonance Imaging and Cardiovascular Computed Tomography in Assessment of Prognostic Factors in ACHD}

Ventricular size and function obtained by MRI are well-known prognostic factors of adverse outcomes such as mortality and other adverse events in many groups of patients with congenital heart diseases. Especially accurate quantification of right ventricle size and function and pulmonary regurgitation is particularly important in patients with tetralogy of Fallot, transposition of the great arteries (TGA) and systemic right ventricle (14, 19-23). Ortega et al. compared data from cardiac magnetic resonance (CMR) between patients with repaired ToF with $(n=13)$ and a control group without $(n=26)$ histories of death and sustained ventricular tachycardia (VT), finding that left ventricle synchrony measured with CMR tissue tracking is associated with death and VT (20). Rathod et al. on the other hand retrospectively reviewed CMR data of patients with Fontan circulation $(n=$ 215), revealing that increased ventricular indexed end-diastolic volumes (>125 mL/body surface area) are not risk factors of elevated mortality or transplant (24). Van der Bom et al. published data showing that right ventricular end-diastolic volume index higher than $150 \mathrm{ml} / \mathrm{m}^{2}$ is associated with increased risk of adverse events in patients with a systemic right ventricle (25). Impaired longitudinal strain of left and right ventricle measured by MRI also seems to be closely related to higher risk 
of adverse events (26). In a population of post-fontan operation patients, end diastolic volume index, end systolic volume index, contractility, mass index and increased afterload were identified as independent factors of higher morbidity and mortality (27). A recent study showed that stroke volume $(\mathrm{SV})$ ratio $(<0.95$; $\mathrm{SV}$ of the two whole ventricles/SV of the right ventricle + SV of the left ventricle), aorta arising from the right ventricle conus, biventricular ejection fraction $(<0.45)$, and left ventricular indexed end-diastolic volume $\left(>73 \mathrm{~mL} / \mathrm{m}^{2}\right)$ calculated using MRI can be used as predictive factors of cardiac events in patients with biventricular heart after Fontan surgery (28). Results of single studies suggest that the deformation imaging technique in MRI and myocardial fibrosis assessed by late gadolinium enhancement and T1 mapping may be very helpful prognostic tools in the future $(20,29-34)$. Increased late gadolinum enhancement of the left ventricle in patients with repaired ToF is related to myocardial dysfunction and is associated with adverse outcomes after correcting for age (34). Additionally, in patients with ToF and pulmonary arterial hypertension its location at the right ventricular insertion points is thought to reflect a more advanced disease and poor prognosis (29). Correlation between septal interstitial expansion representing diffuse fibrosis with NTproBNP levels and chronotropic index in patients with a systemic right ventricle after correction of TGA seems to play role in the development of RV systolic impairment (31).

Cardiovascular computed tomography (CCT) is particularly useful in dissection, pulmonary embolism, and paravalvular abscess in the setting of endocarditis, where it may have advantages over echocardiography and CMR due to being less susceptible to prosthetic valve artifact. It is useful in assessment of coronary artery pathology and collaterals (35) (Table 1).

\section{Cardiopulmonary Exercise Testing (CPET, CPX) in Assessment of Prognostic Factors in ACHD}

CPET, including assessment of objective exercise capacity (peak oxygen consumption peak $\mathrm{VO}_{2}$ ), ventilatory efficiency [ventilation to carbon dioxide output $\left(\mathrm{VE} / \mathrm{VCO}_{2}\right)$ slope], chronotropic and blood pressure response, as well as exerciseinduced arrhythmia and desaturation, improve the assessment of functional capacity and physical fitness and correlate well with morbidity and mortality in ACHD patients (7). The peak $\mathrm{VO}_{2}$ is one of the most useful and potent prognostic factor due to its strong association with increased risk of heart failure, hospitalization and mortality in $\mathrm{ACHD}$ (7, 36-39). According to data presented by Diller et al. peak $\mathrm{VO}_{2}<15.5 \mathrm{ml} \bullet \mathrm{kg}^{-1} \bullet \mathrm{min}^{-1}$ was associated with the greatest risk of hospitalization or death and death alone in adults with congenital heart diseases (7). In the population of patients with Ebstein anomaly peak $\mathrm{VO}_{2}$ relates to severity of the underlying disease (38). $\mathrm{VO}_{2} \leq 52.3 \%$ of predicted value was associated with higher 4-year risk of death or cardiac related emergency hospital admission in patients after a Mustard and Senning operation (39). In the whole population of $\mathrm{CHD}$ patients peak $\mathrm{VO}_{2}$ is reduced $(37,40,41)$ to differing degrees depending on the type of heart defect $(37,41,42)$. Kempny et al. published data showing that peak $\mathrm{VO}_{2}$ was lowest in the Eisenmenger population and complex lesions including univentricular hearts and patients with cyanosis (mean $\pm \mathrm{SD}$ :
TABLE 1 | Potential heart failure prognostic factors in patients with congenital heart disease.

\begin{tabular}{|c|c|c|}
\hline & Parameters & References \\
\hline Transthoracic echocardiography & $\begin{array}{l}\text { - Ventricular and atrial } \\
\text { anatomy } \\
\text { - Systolic ventricular } \\
\text { function } \\
\text { - Systolic to diastolic } \\
\text { duration ratio } \\
\text { - Shunt lesions } \\
\text { - Valvular defects } \\
\text { - Pericardial effusion } \\
\text { - LS }\end{array}$ & $\begin{array}{l}(3,8,10,16,17) \\
(3,9,11) \\
(13) \\
(3,18) \\
(3,12) \\
(18) \\
(14,15)\end{array}$ \\
\hline Magnetic resonance imaging & $\begin{aligned} & \text { - } \text { Anatomy } \\
& \text { - Ventricular function } \text { (R/L VEF, R/L VEDV, } \\
& \text { R/L VEDV index) } \\
& \text { - } \text { Mass index } \\
& \text { - R/L LS } \\
& \text { - SV ratio } \\
& \text { - } \text { Myocardial scarring } \\
& \text { and fibrosis } \\
& \text { - } \text { T1 mapping }\end{aligned}$ & $\begin{array}{l}(3,22,23) \\
(3,19,22,23,25,27, \\
28) \\
(3,23,27) \\
(3,26) \\
(28) \\
(3,29,31,34) \\
(3,30)\end{array}$ \\
\hline Cardiopulmonary exercise testing & $\begin{array}{l}\text { - } \mathrm{VO}_{2} \text { peak } \\
\text { - VENCO } \mathrm{VO}_{2} \text { slope } \\
\text { - Peak HR } \\
\text { - } \mathrm{HRR} \\
\text { - } \mathrm{HRr} \\
\text { - W } \\
\text { - Maximal sBP } \\
\text { - Saturation } \\
\text { - Mean peak RER } \\
\text { - Borg scale } \\
\text { - OUES } \\
\text { - VO }{ }_{2} \text { WR } \\
\text { - VAT }\end{array}$ & $\begin{array}{l}(3,7,36-43) \\
(3,36,39,44,45) \\
(3,36,38,42,46-49) \\
(3,36,38,42,46-49) \\
(3,36,38,42,46-49) \\
(51) \\
(25) \\
(3,36,50) \\
(51) \\
(51) \\
(51) \\
(51) \\
(51)\end{array}$ \\
\hline Biomarkers & $\begin{array}{l}\text { - NT-proBNP } \\
\text { - GDF-15 } \\
\text { - hs-TnT } \\
\text { - RDW } \\
\text { - Galectin-3 } \\
\text { - Ang-2 } \\
\text { - ADMA } \\
\text { - hsCRP }\end{array}$ & $\begin{array}{l}(3,6,55-59) \\
(57,60-63) \\
(3,57,64) \\
(65,66) \\
(67) \\
(68) \\
(69) \\
(3,70)\end{array}$ \\
\hline
\end{tabular}

$L S$, longitudinal systolic strain; $R / L$, right/left; VEF, ventricular ejection fraction; $V E D V$ ventricular end diastolic volume; SV, stroke volume; $V_{2}$, oxygen uptake; $V E N \mathrm{VO}_{2}$, ventilatory efficiency; $H R$, heart rate; $H R R$, heart rate reserve; $H R r$, heart rate recovery; $W$, peak load; $S B P$, systolic blood pressure; RER, respiratory exchange ratio; OUES, oxygen uptake efficiency slope; $\mathrm{VO}_{2} / W R$, oxygen uptake to work rate; VAT, ventilatory anaerobic threshold; NT-proBNP, N-terminal pro-brain type natriuretic peptide; GDF15, growth-differentiation factor 15; hs-TnT, high-sensitivity troponin $T$; RDW, red cell distribution width; Ang-2, angiopoietion-2; ADMA, asymmetrical dimethylarginine; hsCRP, high-sensitivity C-reactive protein.

$43 \pm 13$ and $46 \pm 16 \%$ of predicted peak $\mathrm{VO}_{2}$, respectively) and highest in TGA patients after an arterial switch operation, patients with various forms of valvular heart disease and repaired aortic coarctation (mean \pm SD: $89 \pm 22,80 \pm 30$, and 78 $\pm 25 \%$ of predicted peak $\mathrm{VO}_{2}$, respectively) (41). Diller et al. reported that peak $\mathrm{VO}_{2}$ was normal in only $1 \%$ and borderline in $2.7 \%$ of patients with Fontan circulation (42). Recently published data have demonstrated a strong inverse relation of NYHA class with $\mathrm{VO}_{2}$ peak and additionally with oxygen uptake efficiency 
slope (OUES) and double product at peak exercise (product of heart rate and systolic blood pressure). However, there was also high inconstancy in exercise capacity measured in various NYHA classes (43). Dimopoulos et al. published data showing that $\mathrm{CHD}$ patients presented higher $\mathrm{VE} / \mathrm{VCO}_{2}$ slope than healthy individuals and simultaneously revealed $\mathrm{VE} / \mathrm{VCO}_{2}$ slope as the most potent predictor of mortality in non-cyanotic patients (2year survival of $86 \%$ with $\mathrm{VE} / \mathrm{VCO}_{2}$ slope $>38$ vs. $99 \%$ with $\mathrm{VE} / \mathrm{VCO}_{2}$ slope $<38$ ) (44), which was also presented in a study by Inuzuka et al. (36). In cyanotic ACHD $\mathrm{VE} / \mathrm{VCO}_{2}$ slope did not have predictive ability $(36,44)$. Predictive value of $\mathrm{VE} / \mathrm{VCO}_{2}$ slope has been confirmed in the population of repaired ToF patients $\left(\mathrm{VE} / \mathrm{VCO}_{2}\right.$ slope $\geq 31$ alongside peak $\mathrm{VO}_{2} \% \leq 65 \%$ and QRS duration $\geq 170 \mathrm{~ms}$ were associated with the best sensitivity and specificity to predict adverse outcome) (45) and TGA patients after a Mustard and Senning operation $\left(\mathrm{VE} / \mathrm{VCO}_{2} \geq 35.4\right.$ and $\mathrm{VO}_{2} \% \leq 52.3 \%$ were associated with an increased 4 -year risk of death/cardiac-related emergency hospital admission; 4year event rate of $78.8 \%$ ) (39). Also, heart rate response in the ACHD population may be abnormal $(36,46-48)$. Diller et al. in a population of 727 ACHD patients found abnormal heart rate response to be associated with greater risk of death and to affect $62 \%$ of the population-the lowest prevalence was observed in patients with ventricular septal defect, Ebstein anomaly, transposition of the great arteries and the highest in patients with complex, cyanotic and uncorrected defects (46). Reduced values of such parameters as peak heart rate, heart rate reserve (HRR), and heart rate recovery have been introduced as predictors of mortality $(38,42,46,49)$. Especially, abnormal heart rate reserve puts ACHD patients in a higher risk group. What is interesting, in patients with Eisenmenger syndrome neither $\mathrm{HRR}$ nor $\mathrm{VO}_{2}$ peak was able to predict prognosis (46). Radojevic et al. published data showing that heart rate reserve $<25$ beats per minute was of predictive value in patients with Ebstein anomaly (38) and in the analysis of Diller et al. HRR (with a cut-off value of 72 beats per minute) was suggested to be the only significant prognostic marker for mortality or transplantation in contrast to any other parameter of CPET in the population of Fontan patients (42). A study involving 345 ACHD patients showed that chronotropic incompetence (defined as the inability to achieve $80 \%$ of the predicted maximal heart rate) placed patients in a higher NYHA class and was related to higher NT-proBNP levels and lower $\mathrm{VO}_{2}$ peak (49). Single studies point out other measurements in specific CHD groups that may be important: peak systolic blood pressure during uppermost exercise lower than $180 \mathrm{mmHg}$ combined with a right ventricular end-diastolic volume index above 150 $\mathrm{mL} / \mathrm{m}^{2}$ in patients with a systemic right ventricle $(25),>5 \%$ decrease in saturation during exercise or to $<90 \%(36,50)$. Buys et al. compared ACHD (coarctation of the aorta, ToF, dextroTGA, and univentricular heart) with healthy adults and found mean peak respiratory exchange ratio (RER), median Borg scale, oxygen uptake efficiency slope (OUES), oxygen uptake $\left(\mathrm{VO}_{2}\right)$ to work rate (WR) relationship and ventilatory anaerobic threshold (VAT) to be notably reduced in the CHD population (lowest in univentricular heart population) (51). This leaves an open field for further investigations of these parameters and many others for which we could not find any studies that assessed their statistical significance in risk stratification. Serial exercise testing might be a part of long-term follow-up protocols in ACHD patients. It plays an important role in the timing of interventions and reinterventions (3).

\section{Six Minutes Walk Test in Assessment of Exercise Tolerance in ACHD}

The 6-min walk test (6MWT) is another simple test for quantification of exercise capacity; it relates to outcome in patients with pulmonary arterial hypertension (2, 3). Kempny et al. showed that patients with Eisenmenger syndrome who had baseline saturation below $85 \%$ or did not reach $350 \mathrm{~m}$ in the 6-min walk test (6MWT) had 3 times greater risk of death (52). In Eisenmenger patients with reduced exercise capacity (6MWT distance $<450 \mathrm{~m}$ ), a treatment strategy with initial endothelin receptor antagonist monotherapy should be considered followed by combination therapy if patients fail to improve (3). The 6-min walk tests performed in patients with CHD have revealed a correlation with concentration of BNP. Additionally, there have been established a cut-off value $(450 \mathrm{~m})$ that allows one to categorize patients into groups of BNP concentration below or above $100 \mathrm{pg} / \mathrm{ml}$ (53). Another study concerning 6MWT established a cut-off value $(482 \mathrm{~m})$ of $6 \mathrm{MWT}$ distance that was able to select patients with reduced $\mathrm{VO}_{2}$ peak (54). Moreover, multivariate regression analysis distinguished the $6 \mathrm{MWT}$ distance and NYHA classes as significant predictors of $\mathrm{VO}_{2}$ peak (Figure 1) (54).

\section{Biochemical Markers in ACHD}

In $\mathrm{CHD}$ patients, natriuretic peptides [B-type natriuretic peptide (BNP) and N-terminal-pro-BNP (NT-pro-BNP)] are best studied and especially useful in patients with biventricular circulation and less useful in patients with a Fontan circulation (55). Eindhoven et al. published data showing that N-terminal probrain type natriuretic peptide (NT-proBNP) levels depend on diagnosis and are strongly associated with echocardiographic parameters and exercise capacity (56). Therefore, BNP and NTproBNP are very important prognostic factors of mortality and may be a helpful tool for risk stratification and monitoring $\mathrm{ACHD}$, as more and more other studies confirm (6, 57-59). In patients with heart failure, BNP/NT-proBNP were related to age, and BNP was more related to age than NT-proBNP. However, the influence of age on the levels of all natriuretic peptides was modest, and comparable to several other factors (71). Popelova et al. published data showing that the best discrimination value of NT-proBNP for mortality prediction in ACHD was $630 \mathrm{pg} / \mathrm{ml}$ (74 pmol/L; sensitivity 74\%, specificity $84 \%$ ) (58). Additionally, baseline measurements of NT-proBNP were closely related to increased risk of death $(58,59)$. Nevertheless, NT-proBNP level below $15.2 \mathrm{pmol} / \mathrm{L}$ can assuredly place patients in the low risk category of death or heart failure (57). In the study of Baggen et al. it was found that changes of NT-proBNP levels were associated with higher risk of adverse events. The annual increase of $\sim 25 \%$ of the baseline value is suggested to be of clinical importance. Interestingly, some patients (25\%) with the greatest decline in NT-proBNP levels also were at higher risk of adverse events (59). In the position paper of the working group of grown-up 


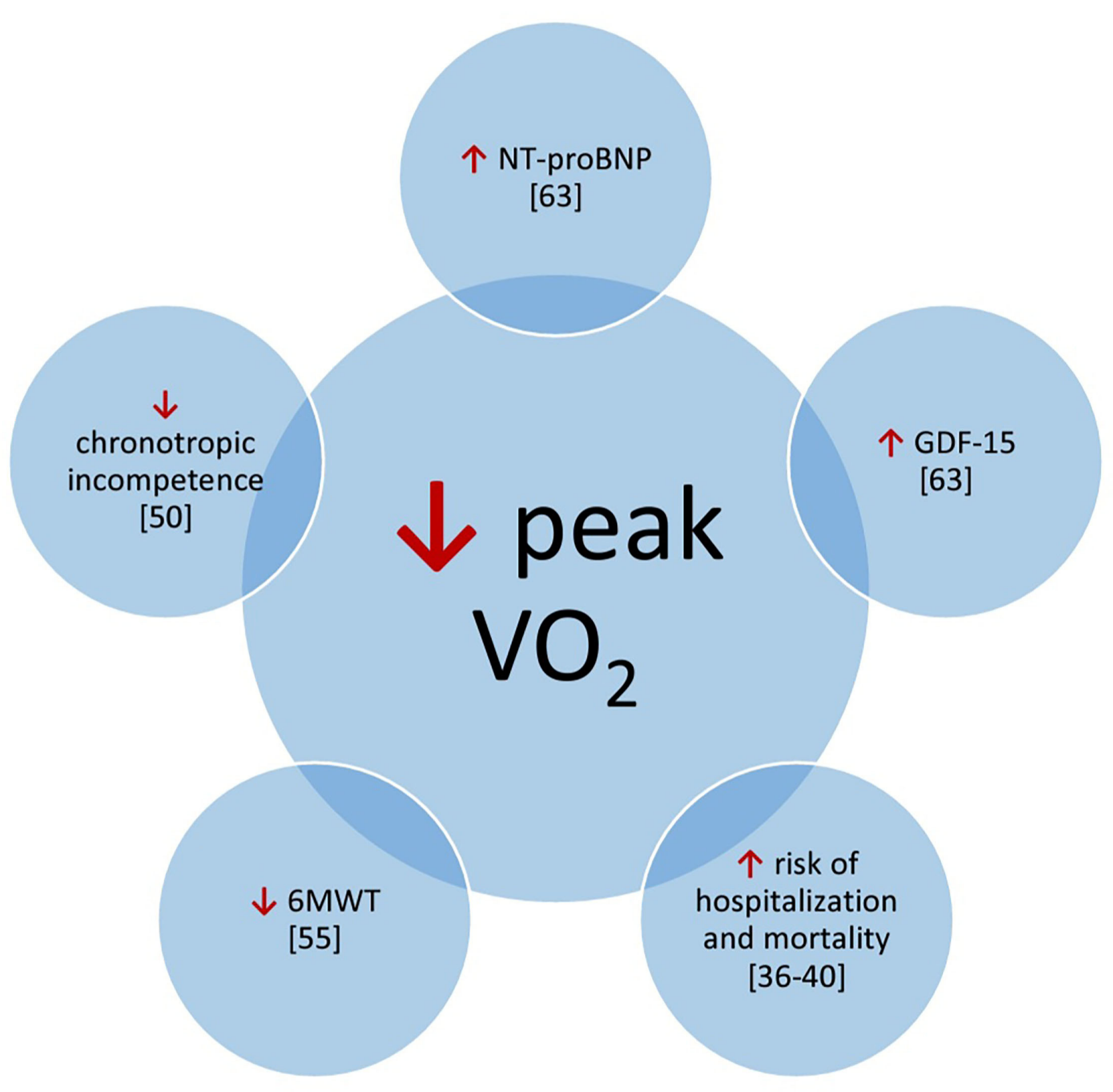

FIGURE 1 | Potential correlations of prognostic factors with peak V02. 6MWT, 6 minute walk test; GDF-15, growth-differentiation factor 15; NT-proBNP, N-terminal pro-bra in type natriuretic peptide.

congenital heart disease and the heart failure association of the European Society of Cardiology, it was proposed that in ACHD a double increase in NT-proBNP level within 6 months should be considered as a significant rise (6). NT-proBNP should be the basic parameter assessed in the population of ACHD-elevated levels and, above all, increases in time are prognostically relevant in ACHD. Serial testing of natriuretic peptides plays a role in identifying patients at risk for adverse events. There are also other biomarkers that potentially can be used to predict adverse outcomes. Data presented by Baggen et al. have shown that patients with the highest levels of GDF-15 (growth differentiation factor 15) (fourth quartile; >867 ng/L) had remarkably higher risk of unfavorable events in comparison with the lowest levels (first quartile; $<487 \mathrm{ng} / \mathrm{L}$ ). They also presented data showing a correlation between NT-proBNP and GDF-15 $(r=0.50)(57)$. In the study of Norozi, levels of growth differentiation factor 15 (GDF-15) were compared within subgroups of $\mathrm{VO}_{2} \max (<65 \%$, $65-85 \%,>85 \%)$ and NT-proBNP $(<100,100-300,>300$ pg/mL). As a result, levels of GDF-15 corresponded with levels of NTproBNP and values of $\mathrm{VO}_{2}$ max - the highest mean GDF-15 was in groups of $\mathrm{VO}_{2} \max <65 \%$ and NT-proBNP $>300 \mathrm{pg} / \mathrm{mL}$, the lowest in groups of $\mathrm{VO}_{2} \max >85 \%$ and NT-proBNP $<100$ 
TABLE 2 | Congenital heart diseases and their prognostic factors in selected ACHD.

\begin{tabular}{|c|c|c|}
\hline CHD & Parameters & References \\
\hline Tetralogy of Fallot & $\begin{array}{l}\text { - Ventricular function and } \\
\text { anatomy } \\
\text { - QRS complex width } \\
\text { - Size and function of the left } \\
\text { atrium } \\
\text { - LS } \\
\text { - Tricuspid/pulmonary valve } \\
\text { regurgitation } \\
\text { - Left ventricular dyssynchrony } \\
\text { (MRI) } \\
\text { - Increased late gadolinium } \\
\text { enhancement of the left } \\
\text { ventricle (MRI) } \\
\text { - Peak VO} \\
\text { - VENCO }{ }_{2} \text { slope } \\
\text { - Heart rate response } \\
\text { - Oxygen saturation } \\
\text { - NT-proBNP and another } \\
\text { biochemical parameters }\end{array}$ & $\begin{array}{l}(3,4,8,9) \\
(9,45) \\
(3,4,10) \\
(11) \\
(12) \\
(20) \\
(34)\end{array}$ \\
\hline $\begin{array}{l}\text { Transposition of } \\
\text { the great artieries }\end{array}$ & $\begin{array}{l}\text { - Ventricular function and } \\
\text { anatomy } \\
\text { - Systemic right ventricular LS } \\
\text { - Right ventricular end-diastolic } \\
\text { volume index } \\
\text { - Diffuse fibrosis (MRI) } \\
\text { - Peak } \mathrm{VO}_{2} \\
\text { - VENCO } \mathrm{VO}_{2} \text { slope } \\
\text { - Heart rate response } \\
\text { - Peak exercise systolic blood } \\
\text { pressure } \\
\text { - NT-proBNP and another } \\
\text { biochemical parameters }\end{array}$ & $\begin{array}{l}(3,4,8) \\
(14,15,26) \\
(25) \\
(31) \\
(3,4,7,36,37,39,41,42) \\
(3,4,39,44) \\
(3,4,46) \\
(25) \\
(3,4,6,55-71)\end{array}$ \\
\hline $\begin{array}{l}\text { Post-fontan } \\
\text { procedure }\end{array}$ & $\begin{array}{l}\text { - Ventricular function and } \\
\text { anatomy } \\
\text { - Systolic to diastolic duration } \\
\text { ratio } \\
\text { - End diastolic and systolic } \\
\text { volume index (MRI) } \\
\text { - Contractility (MRI) } \\
\text { - Mass index (MRI) } \\
\text { - Increased afterload (MRI) } \\
\text { - Stroke volume ratio in } \\
\text { biventricular heart (MRI) } \\
\text { - Aorta arising from the right } \\
\text { ventricle conus in biventricular } \\
\text { heart (MRI) } \\
\text { - Biventricular ejection fraction } \\
\text { (MRI) } \\
\text { - Left ventricular indexed } \\
\text { end-diastolic volume in } \\
\text { biventricular heart (MRI) } \\
\text { - Peak VO } 2 \\
\text { - VENCO }{ }_{2} \text { slope } \\
\text { - Heart rate response } \\
\text { - Oxygen saturation } \\
\text { - NT-proBNP and another } \\
\text { biochemical parameters } \\
\text { - Liver function }\end{array}$ & $\begin{array}{l}(28) \\
(28) \\
\\
(28) \\
(3,4,7,36,37,41,42) \\
(3,4,7,36,37,44) \\
(3,4,42,46) \\
(3,4) \\
(3,4,6,55-71) \\
(3,4)\end{array}$ \\
\hline Ebstein anomaly & $\begin{array}{l}\text { - Ventricular function and } \\
\text { anatomy } \\
\text { - Peak } \mathrm{VO}_{2}\end{array}$ & $\begin{array}{l}(3,4,8) \\
(3,4,7,36-38,41,42) \\
(3,4,7,36,37,44)\end{array}$ \\
\hline
\end{tabular}

(Continued)
TABLE 2 | Continued

\begin{tabular}{lll}
\hline CHD & Parameters & References \\
\hline & - VENCO 2 slope & $(3,4,38,46)$ \\
- & Heart rate response & $(3,4)$ \\
- & Oxygen saturation & $(3,4,6,55-71)$ \\
- & NT-proBNP and another & \\
& biochemical parameters & \\
Eisenmenger & - Ventricular function and & $(3,4,8)$ \\
syndrome & anatomy & \\
- & Right/left/biventricular function & $(19)$ \\
- & TAPSE & $(3,4,16,17)$ \\
- & Right ventricular effective & $(16,17)$ \\
& systolic to diastolic duration & \\
& ratio & \\
- & Right atrial area & $(16,17)$ \\
- & Right atrial to left atrial area & $(16,17)$ \\
- & Pericardial effusion & $(18)$ \\
- & Pretricuspid shunt & $(3,4,18)$ \\
- & Oxygen saturation & $(3,4,19)$ \\
- & Peak VO 2 & $(3,4,7,36,37,41,42)$ \\
- & $6-$-min walk test & $(52)$ \\
- & NT-proBNP and another & $(3,4,6,55-71)$ \\
& biochemical parameters &
\end{tabular}

$L S$, Iongitudinal systolic strain; $V_{2}$, oxygen uptake; $V E N C C_{2}$, ventilatory efficiency; NT-proBNP, N-terminal pro-brain type natriuretic peptide.

$\mathrm{pg} / \mathrm{mL}$ (60). Eindhoven et al. published data showing its positive correlation with NT-proBNP $(r=0.445, p<0.001)$. Additionally, level of GDF-15 higher than the reference value $(1,109 \mathrm{ng} / \mathrm{L})$ was associated with NYHA class and decreased exercise capacity (61). One study conducted in a child population also showed that plasma GDF-15 levels were positively correlated with concentration of NT-proBNP $(r=0.810 ; p<0.01)$ and negatively with left ventricular ejection fraction $(r=-0.391 ; p<0.01)(62)$. Interestingly, GDF-15 was also higher in patients with elevated pulmonary pressure (median $1,114 \mathrm{ng} / \mathrm{L}$ ) in relation to patients with normal pulmonary pressure (median $606 \mathrm{ng} / \mathrm{L}$ ) (61) and was associated with thromboembolic events (57). This was confirmed in a child population in which $\mathrm{Li}$ et al. detected significantly elevated levels of GDF-15 in patients with pulmonary arterial hypertension secondary to CHD (median 1,415 vs. $890.6 \mathrm{ng} / \mathrm{L}$; $p<0.01$ ) (63). Thus, GDF-15 and its correlation with NTproBNP and $\mathrm{VO}_{2}$ might be potentially a substitute marker for identifying CHD patients at risk of heart failure. Also, a correlation of high-sensitivity troponin $\mathrm{T}$ (hs-TnT) and NTproBNP has been presented by Eindhoven et al. (64) $(r=0.400$, $p<0.001)$ and Baggen et al. (57) $(r=0.42)$. Elevated levels of hs-TnT ( $>14 \mathrm{ng} / \mathrm{L})$ has also been observed in patients with systemic systolic dysfunction, non-sinus rhythm, second and higher NYHA class and especially systemic right ventricle or elevated pulmonary pressures (64). Baggen et al. stated that we may use NT-proBNP as a conventional risk marker (especially with its high negative predictive value) but we may use GDF-15 and hs-TnT in order to further identify patients in the highest cardiovascular risk - a combination of elevated concentrations of NT-proBNP, GDF-15 (>1,109 ng/L) and hs-TnT (>14 ng/L) placed patients with $\mathrm{CHD}$ in a group of the highest risk of adverse 
events (57). Hs-TnT alongside GDF-15 also seems to correlate with NT-proBNP. Therefore, one should take into cosideration not only NT-proBNP but also GDF-15 and hs-TnT because by assessing all three parameters, one is more likely to select the highest-risk patients. There are more parameters that might be of use in the future. Two recent studies have shown that elevated red cell distribution width (RDW) is a significant and independent predictor of adverse events in ACHD and thus may be used as another marker in risk stratification of this population, and taking into account that this parameter is available easily and with minimal cost in all laboratories and ambulatories, it might be a first line screening tool $(65,66)$. Galectin-3 is another biomarker which might be useful in risk stratification of CHD patients. Baggen et al. published data showing its association with age, cardiac medication use, NYHA classification, loss of sinus rhythm, cardiac dysfunction, NT-proBNP and adverse cardiovascular events, but this association disappeared after adjustment for NT-proBNP (67). Angiopoietin-2 (Ang-2) is also a potential marker for heart failure in the CHD population. Lukasz et al. found that levels of Ang-2 reached a statistically significant difference in patients with normal ventricular function compared to a group with severe ventricular dysfunction (3.53 $\pm 4.19 \mathrm{ng} / \mathrm{ml}$ vs. $7.48 \pm 7.57 \mathrm{ng} / \mathrm{ml}, p<0.05)$ and patients in NYHA class I $(2.52 \pm 1.6 \mathrm{ng} / \mathrm{ml})$ compared to NYHA class II $(6.83 \pm 6.56 \mathrm{ng} / \mathrm{ml}, p<0.0001)$ as well as NYHA class III $(8.23 \pm 6.88 \mathrm{ng} / \mathrm{ml}, p<0.0001)$. Ang- 2 was also elevated in patients with limited cardiopulmonary exercise. Additionally, elevated concentrations of Ang-2 were observed in patients with single ventricle physiology $(11.21 \pm 6.94 \mathrm{ng} / \mathrm{ml})$ compared to those with a systemic left $(2.93 \pm 2.75 \mathrm{ng} / \mathrm{ml}, p<0.0001)$ or right ventricle $(4.86 \pm 5.22 \mathrm{ng} / \mathrm{ml}, p<0.0001)$, unlike NTproBNP. Ang-2 is a promising biomarker, especially in the population of Fontan patients (68). Ang-2 Tutarel et al. published data suggesting asymmetrical dimethylarginine (ADMA) to be remarkably elevated in the $\mathrm{CHD}$ population and to be superior to NT-proBNP in differentiation of NYHA class and at least as good for assessment of exercise capacity in the CHD population. There were significant differences in ADMA levels between NYHA class I $(0.44 \pm 0.06 \mathrm{mmol} / \mathrm{l})$ and NYHA class II $(0.48 \pm 0.08 \mathrm{mmol} / \mathrm{l}$, $p=0.04)$ and III $(0.54 \pm 0.10 \mathrm{mmol} / \mathrm{l}, p<0.001)$, as well as between NYHA class II and III $(p=0.02)$. Differences in NTproBNP were also significant but not between NYHA class II and III. (69). A single study conducted by Opotowsky et al. showed that high-sensitivity CRP (hsCRP) level in the highest quartile $(\geq 2.98 \mathrm{mg} / \mathrm{L})$ is associated with inferior functional status and exercise capacity and increased risk for death, and most of all, is an independent risk factor of adverse cardiovascular events and all-cause mortality. Additionally, excluding patients with very high levels of hsCRP (potential infection; $\geq 10.0 \mathrm{mg} / \mathrm{L}$ ) and women using estrogen-containing medications from the analysis had no effect on the results (70).

\section{Risk Prediction Scales in ACHD}

Some investigators have already tried to develop or apply existing scales and models of adverse outcomes risk prediction and poor exercise capacity to the population of CHD patients $(36,72-75)$. Yap et al. identified risk factors (poor functional class, pulmonary hypertension, valvular heart disease, single-ventricle physiology) in adults with CHD and atrial arrhythmias and based on them created a risk score (1 point for each predictor; 0-low risk, 1 -moderate risk, $>1$ high risk) (72). The Low Heart Failure Survival Score has been found to be correlated with adverse events but has not been successful in adequate risk stratification in the CHD population (73). The Seattle Heart Failure Model also seems to not fully represent actual survival of patients with CHD (74). Another study showed no significant differences between the ABILITY index (it scores and assigns patients on their capacity to work, capacity to be active, and ability to go through uncomplicated pregnancies-if applicable; it assigns patients to 4 classes) and NYHA classification in assessing the CHD population (75). Nevertheless, they can be used as a help in identifying patients who are at greater risk of adverse events, but more studies are needed in order to achieve more accurate prediction. Still, it is very important to find a parameter or group of parameters on the basis of which it would be possible to define in an objective and simple way the degree of functional limitation in ACHD like the New York Heart Association classification in heart failure patients.

In ACHD patients any haemodynamic abnormalities, including arrhythmias, potentially causing heart failure that can be addressed by intervention or surgery must be excluded. The structural interventions not pharmacological treatment are the therapy of choice in this group of patients. There is the need for personalized risk assessment in ACHD involving not only signs of heart failure and/or arrhythmia but also accurate diagnosis of residual defects and possibilities of their interventional treatment and typing the best time for intervention. No ideal risk stratification scheme has so far been developed. The future perspectives regarding ACHD risk assessment should take into account arrhythmias monitoring, serial cardiopulmonary exercise testing for objective assessment of exercise intolerance, the serial assessment of biochemical biomarkers and perhaps in the future also genetic may be additional reasonable tool. Echocardiographic and other imaging markers needs personalization depending of the type of congenital heart defect (Table 2).

\section{CONCLUSIONS}

There is no possibility at the moment to assess and monitor ACHD with a single parameter or a simple scale that would apply to the whole population like the NYHA classification in heart failure patients. Patients with $\mathrm{CHD}$ are heterogeneous population and personalized assessment of patients' functional state is important not only for their diagnosis and management, but also for prognostic reasons. Considering all available diagnostic tools, selected CPET parameters, echocardiography and magnetic resonance imaging as well as NT-proBNP and GDF15 levels are valuable assessment tools of ACHD patients which provide the most information about patients and their prognosis. The most promising CPET parameters seem to be peak $\mathrm{VO}_{2}, \mathrm{VE} / \mathrm{VCO}_{2}$, heart rate reserve. Due to the heterogeneity of this group of patients, relatively small amount of medical centers dealing with 
congenital heart diseases, lack of large multi-center studies and uneven access of medical centers to all presented factors, it is a very difficult task to create uniform rules for managing and monitoring the population of $\mathrm{CHD}$ patients.

\section{AUTHOR CONTRIBUTIONS}

$\mathrm{PL}, \mathrm{MB}, \mathrm{MM}$, and $\mathrm{AB}-\mathrm{D}$ contributed to conception and design of the paper. PL and AB-D managed the literature research. PL

\section{REFERENCES}

1. Ávila P, Mercier LA, Dore A, Marcotte F, Mongeon FP, Ibrahim R, et al. Adult congenital heart disease: a growing epidemic. Can J Cardiol. (2014) 30(Suppl. 12):S410-9. doi: 10.1016/j.cjca.2014.07.749

2. Zomer AC, Vaartjes I, van der Velde ET, De Jong HM, Konings TC, Wagenaar LJ, et al. Heart failure admissions in adults with congenital heart disease; risk factors and prognosis. Int J Cardiol. (2013) 168:248793. doi: 10.1016/j.ijcard.2013.03.003

3. Baumgartner H, De Backer J, Babu-Narayan SV, Budts W, Chessa M, Diller GP, et al. 2020 ESC Guidelines for the management of adult congenital heart disease. Eur Heart J. (2021) 42:563-645. doi: 10.1093/eurheartj/ehaa554

4. Stout KK, Daniels CJ, Aboulhosn JA, Bozkurt B, Broberg CS, Colman JM, et al. 2018 AHA/ACC guideline for the management of adults with congenital heart disease: a report of the American College of Cardiology/American Heart Association Task Force on Clinical Practice Guidelines. Circulation. (2019) 139:e698-800. doi: 10.1161/CIR.0000000000000683

5. Piran S, Veldtman G, Siu S, Webb GD, Liu PP. Heart failure and ventricular dysfunction in patients with single or systemic right ventricles. Circulation. (2002) 105:1189-94. doi: 10.1161/hc1002.105182

6. Budts W, Roos-Hesselink J, Rädle-Hurst T, Eicken A, McDonagh TA, Lambrinou E, et al. Treatment of heart failure in adult congenital heart disease: a position paper of the Working Group of Grown-Up Congenital Heart Disease and the Heart Failure Association of the European Society of Cardiology. Eur Heart J. (2016) 37:1419-27. doi: 10.1093/eurheartj/ehv741

7. Diller G-P, Dimopoulos K, Okonko D, Li W, Babu-Narayan SV, Broberg CS, et al. Exercise intolerance in adult congenital heart disease: comparative severity, correlates, and prognostic implication. Circulation. (2005) 112:828-35. doi: 10.1161/CIRCULATIONAHA.104.529800

8. Koyak Z, Harris L, de Groot JR, Silversides CK, Oechslin EN, Bouma BJ, et al. Sudden cardiac death in adult congenital heart disease. Circulation. (2012) 126:1944-54. doi: 10.1161/CIRCULATIONAHA.112.104786

9. Ghai A, Silversides C, Harris L, Webb GD, Siu SC, Therrien J. Left ventricular dysfunction is a risk factor for sudden cardiac death in adults late after repair of tetralogy of Fallot. J Am Coll Cardiol. (2002) 40:167580. doi: 10.1016/S0735-1097(02)02344-6

10. Baggen VJM, Schut AW, Cuypers JAAE, Witsenburg M, Boersma E, van den Bosch AE, et al. Prognostic value of left atrial size and function in adults with tetralogy of Fallot. Int J Cardiol. (2017) 236:12531. doi: 10.1016/j.ijcard.2017.02.153

11. Diller GP, Kempny A, Liodakis E, Alonso-Gonzalez R, Inuzuka R, Uebing A, et al. Left ventricular longitudinal function predicts life-threatening ventricular arrhythmia and death in adults with repaired tetralogy of Fallot. Circulation. (2012) 125:2440-6. doi: 10.1161/CIRCULATIONAHA.111.086983

12. Gatzoulis MA, Balaji S, Webber SA, Siu SC, Hokanson JS, Poile C, et al. Risk factors for arrhythmia and sudden cardiac death late after repair of tetralogy of Fallot: a multicentre study. Lancet. (2000) 356:97581. doi: 10.1016/S0140-6736(00)02714-8

13. Cordina $\mathrm{R}$, von Klemperer $\mathrm{K}$, Kempny A, West C, Senior R, Celermajer DS, et al. Echocardiographic predictors of mortality in adults with a Fontan circulation. JACC Cardiovasc Imaging. (2017) 10:212-3. doi: 10.1016/j.jcmg.2016.03.006

14. Diller GP, Radojevic J, Kempny A, Alonso-Gonzalez R, Emmanouil L, Orwat $\mathrm{S}$ et al. Systemic right ventricular longitudinal strain is reduced in adults wrote the first draft of the manuscript. $M B, M M$, and $A B-D$ reviewed and made corrections to the manuscript. All authors contributed to manuscript final revision, read, and approved the submitted version.

\section{FUNDING}

This project was financed by the Polish Mother's Memorial Hospital Research Institute.

with transposition of the great arteries, relates to subpulmonary ventricular function, and predicts adverse clinical outcome. Am Heart J. (2012) 163:85966. doi: 10.1016/j.ahj.2012.01.038

15. Eindhoven JA, Menting ME, van den Bosch AE, McGhie JS, Witsenburg M, Cuypers JA, et al. Quantitative assessment of systolic right ventricular function using myocardial deformation in patients with a systemic right ventricle. Eur Heart J Cardiovasc Imaging. (2015) 16:380-8. doi: 10.1093/ehjci/jeu194

16. Moceri P, Dimopoulos K, Liodakis E, Germanakis I, Kempny A, Diller GP, et al. Echocardiographic predictors of outcome in Eisenmenger syndrome. Circulation. (2012) 126:14618. doi: 10.1161/CIRCULATIONAHA.112.091421

17. Baggen VJM, Driessen MMP, Post MC, van Dijk AP, Roos-Hesselink JW, van den Bosch AE, et al. Echocardiographic findings associated with mortality or transplant in patients with pulmonary arterial hypertension: a systematic review and meta-analysis. Neth Heart J. (2016) 24:37489. doi: 10.1007/s12471-016-0845-3

18. Kempny A, Hjortshøj CS, Gu H, Li W, Opotowsky AR, Landzberg MJ, et al. Predictors of death in contemporary adult patients with Eisenmenger syndrome: a multicenter study. Circulation. (2017) 135:143240. doi: 10.1161/CIRCULATIONAHA.116.023033

19. Jensen AS, Broberg CS, Rydman R, Diller GP, Li W, Dimopoulos K, et al. Impaired right, left, or biventricular function and resting oxygen saturation are associated with mortality in Eisenmenger syndrome: a clinical and cardiovascular magnetic resonance study. Circ Cardiovasc Imaging. (2015) 8:596. doi: 10.1161/CIRCIMAGING.115.003596

20. Ortega M, Triedman JK, Geva T, Harrild DM. Relation of left ventricular dyssynchrony measured by cardiac magnetic resonance tissue tracking in repaired tetralogy of Fallot to ventricular tachycardia and death. Am J Cardiol. (2011) 107:1535-40. doi: 10.1016/j.amjcard.2011.01.032

21. Partington SL, Valente AM. Cardiac magnetic resonance in adults with congenital heart disease. Methodist Debakey Cardiovasc J. (2013) 9:15662. doi: 10.14797/mdcj-9-3-156

22. Puchalski MD, Williams RV, Askovich B, Minich LL, Mart C, Tani LY. Assessment of right ventricular size and function: echo versus magnetic resonance imaging. Congenit Heart Dis. (2007) 2:27-31. doi: 10.1111/j.1747-0803.2007.00068.x

23. Blalock SE, Banka P, Geva T, Powell AJ, Zhou J, Prakash A. Interstudy variability in cardiac magnetic resonance imaging measurements of ventricular volume, mass, and ejection fraction in repaired tetralogy of Fallot: a prospective observational study. J Magn Reson Imaging. (2013) 38:82935. doi: 10.1002/jmri.24050

24. Rathod RH, Prakash A, Kim YY, Germanakis IE, Powell AJ, Gauvreau K, et al. Cardiac magnetic resonance parameters predict transplantation-free survival in patients with Fontan circulation. Circ Cardiovasc Imaging. (2014) 7:502-9. doi: 10.1161/CIRCIMAGING.113.00 1473

25. van der Bom T, Winter MM, Groenink M, Vliegen HW, Pieper PG, van Dijk $\mathrm{AP}$, et al. Right ventricular end-diastolic volume combined with peak systolic blood pressure during exercise identifies patients at risk for complications in adults with a systemic right ventricle. J Am Coll Cardiol. (2013) 62:92636. doi: 10.1016/j.jacc.2013.06.026

26. Moon TJ, Choueiter N, Geva T, Valente AM, Gauvreau K, Harrild DM. Relation of biventricular strain and dyssynchrony in repaired tetralogy of Fallot measured by cardiac magnetic resonance to death 
and sustained ventricular tachycardia. Am J Cardiol. (2015) 115:67680. doi: 10.1016/j.amjcard.2014.12.024

27. Sieweke JT, Haghikia A, Riehle C, Klages C, Akin M, König T, et al. Prediction of heart failure and death in an adult population of Fontan patients. Cardiol Young. (2019) 29:602-9. doi: 10.1017/S1047951119000258

28. Takahashi T, Shiina Y, Nagao M, Inai K. Stroke volume ratio derived from magnetic resonance imaging as an indicator of interventricular dyssynchrony predicts future cardiac event in patients with biventricular Fontan circulation. Heart Vessels. (2019) 34:114-22. doi: 10.1007/s00380-018-1217-2

29. Freed BH, Gomberg-Maitland M, Chandra S, Mor-Avi V, Rich S, Archer SL, et al. Late gadolinium enhancement cardiovascular magnetic resonance predicts clinical worsening in patients with pulmonary hypertension. J Cardiovasc Magn Reson. (2012) 14:11. doi: 10.1186/1532-429X-14-11

30. Riesenkampff E, Messroghli DR, Redington AN, GrosseWortmann L. Myocardial T1 mapping in pediatric and congenital heart disease. Circ Cardiovasc Imaging. (2015) 8:e002504. doi: 10.1161/CIRCIMAGING.114.002504

31. Plymen CM, Sado DM, Taylor AM, Bolger AP, Lambiase PD, Hughes M, et al. Diffuse myocardial fibrosis in the systemic right ventricle of patients late after Mustard or Senning surgery: an equilibrium contrast cardiovascular magnetic resonance study. Eur Heart J Cardiovasc Imaging. (2013) 14:9638. doi: 10.1093/ehjci/jet014

32. Kempny A, Fernández-Jiménez R, Orwat $\mathrm{S}$, Schuler $\mathrm{P}$, Bunck AC, Maintz D, et al. Quantification of biventricular myocardial function using cardiac magnetic resonance feature tracking, endocardial border delineation and echocardiographic speckle tracking in patients with repaired tetralogy of Fallot and healthy controls. J Cardiovasc Magn Reson. (2012) 14:32. doi: 10.1186/1532-429X-14-32

33. Jing L, Wehner GJ, Suever JD, Charnigo RJ, Alhadad S, Stearns E, et al. Left and right ventricular dyssynchrony and strains from cardiovascular magnetic resonance feature tracking do not predict deterioration of ventricular function in patients with repaired tetralogy of Fallot. J Cardiovasc Magn Reson. (2016) 18:49. doi: 10.1186/s12968-016-0268-8

34. Dobson RJ, Mordi I, Danton MH, Walker NL, Walker HA, Tzemos N. Late gadolinium enhancement and adverse outcomes in a contemporary cohort of adult survivors of tetralogy of Fallot. Congenit Heart Dis. (2017) 12:5866. doi: $10.1111 /$ chd.12403

35. Kilner P, Nichol E, Rubens $\mathrm{M}$. The roles of $\mathrm{CT}$ and CMR in adult congenital heart disease. In: ESC Textbook of Cardiovascular Imaging. 2nd ed. Oxford: Oxford University Press (2015). p. 563-600.

36. Inuzuka R, Diller GP, Borgia F, Benson L, Tay EL, Alonso-Gonzalez R, et al. Comprehensive use of cardiopulmonary exercise testing identifies adults with congenital heart disease at increased mortality risk in the medium term. Circulation. (2012) 125:250-9. doi: 10.1161/CIRCULATIONAHA.111.058719

37. Mantegazza V, Apostolo A, Hager A. Cardiopulmonary exercise testing in adult congenital heart disease. Ann Am Thorac Soc. (2017) 14(Suppl. 1):S93101. doi: 10.1513/AnnalsATS.201611-876FR

38. Radojevic J, Inuzuka R, Alonso-Gonzalez R, Borgia F, Giannakoulas G, Prapa M, et al. Peak oxygen uptake correlates with disease severity and predicts outcome in adult patients with Ebstein's anomaly of the tricuspid valve. Int J Cardiol. (2013) 163:305-8. doi: 10.1016/j.ijcard.2011. 06.047

39. Giardini A, Hager A, Lammers AE, Derrick G, Müller J, Diller GP, et al. Ventilatory efficiency and aerobic capacity predict event-free survival in adults with atrial repair for complete transposition of the great arteries. J Am Coll Cardiol. (2009) 53:1548-55. doi: 10.1016/j.jacc.2009.02.005

40. Guazzi M, Adams V, Conraads V, Halle M, Mezzani A, Vanhees L, et al. European Association for Cardiovascular Prevention \& Rehabilitation; American Heart Association. EACPR/AHA Scientific Statement Clinical recommendations for cardiopulmonary exercise testing data assessment in specific patient populations. Circulation. (2012) 126:2261-74. doi: 10.1161/CIR.0b013e31826fb946

41. Kempny A, Dimopoulos K, Uebing A, Moceri P, Swan L, Gatzoulis MA, et al. Reference values for exercise limitations among adults with congenital heart disease. Relation to activities of daily lifeyitiess centre experience and review of published data. Eur Heart J. (2012) 33:1386-96. doi: 10.1093/eurheartj/ehr461

42. Diller GP, Giardini A, Dimopoulos K, Gargiulo G, Müller J, Derrick G, et al. Predictors of morbidity and mortality in contemporary Fontan patients: results from a multicenter study including cardiopulmonary exercise testing in 321 patients. Eur Heart J. (2010) 31:3073-83. doi: 10.1093/eurheartj/ehq356

43. Das BB, Young ML, Niu J, Mendoza LE, Chan KC, Roth T. Relation Between New York Heart Association functional class and objective measures of cardiopulmonary exercise in adults with congenital heart disease. Am J Cardiol. (2019) 123:1868-73. doi: 10.1016/j.amjcard.2019.02.053

44. Dimopoulos K, Okonko DO, Diller GP, Broberg CS, Salukhe TV, BabuNarayan SV, et al. Abnormal ventilatory response to exercise in adults with congenital heart disease relates to cyanosis and predicts survival. Circulation. (2006) 113:2796-802. doi: 10.1161/CIRCULATIONAHA.105.594218

45. Müller J, Hager A, Diller GP, Derrick G, Buys R, Dubowy KO, et al. Peak oxygen uptake, ventilatory efficiency and QRS-duration predict event free survival in patients late after surgical repair of tetralogy of Fallot. Int J Cardiol. (2015) 196:158-64. doi: 10.1016/j.ijcard.2015.05.174

46. Diller GP, Dimopoulos K, Okonko D, Uebing A, Broberg CS, BabuNarayan S, et al. Heart rate response during exercise predicts survival in adults with congenital heart disease. J Am Coll Cardiol. (2006) 48:12506. doi: 10.1016/j.jacc.2006.05.051

47. Takken T, Blank AC, Hulzebos EH, van Brussel M, Groen WG, Helders PJ. Cardiopulmonary exercise testing in congenital heart disease: (contra)indications and interpretation. Neth Heart J. (2009) 17:38592. doi: 10.1007/BF03086289

48. Trojnarska O, Gwizdała A, Katarzyński S, Katarzyńska A, Oko-Sarnowska Z, Breborowicz P, et al. Evaluation of exercise capacity with cardiopulmonary exercise testing and BNP levels in adult patients with single or systemic right ventricles. Arch Med Sci. (2010) 6:192-7. doi: 10.5114/aoms.2010.13893

49. Norozi K, Wessel A, Alpers V, Arnhold JO, Binder L, Geyer S, et al. Chronotropic incompetence in adolescents and adults with congenital heart disease after cardiac surgery. J Card Fail. (2007) 13:263-8. doi: 10.1016/j.cardfail.2006.12.002

50. Khan AM, Paridon SM, Kim YY. Cardiopulmonary exercise testing in adults with congenital heart disease. Expert Rev Cardiovasc Ther. (2014) 12:86372. doi: $10.1586 / 14779072.2014 .919223$

51. Buys R, Cornelissen V, Van De Bruaene A, Stevens A, Coeckelberghs E, Onkelinx S, et al. Measures of exercise capacity in adults with congenital heart disease. Int J Cardiol. (2011) 153:26-30. doi: 10.1016/j.ijcard.2010.08.030

52. Kempny A, Dimopoulos K, Alonso-Gonzalez R, Alvarez-Barredo M, Tutarel O, Uebing A, et al. Six-minute walk test distance and resting oxygen saturations but not functional class predict outcome in adult patients with Eisenmenger syndrome. Int J Cardiol. (2013) 168:47849. doi: 10.1016/j.ijcard.2013.07.227

53. Niedeggen A, Skobel E, Haager P, Lepper W, Mühler E, Franke A. Comparison of the 6-minute walk test with established parameters for assessment of cardiopulmonary capacity in adults with complex congenital cardiac disease. Cardiol Young. (2005) 15:385-90. doi: 10.1017/S1047951105000818

54. Kehmeier ES, Sommer MH, Galonska A, Zeus T, Verde P, Kelm M. Diagnostic value of the six-minute walk test (6MWT) in grown-up congenital heart disease (GUCH): Comparison with clinical status and functional exercise capacity. Int J Cardiol. (2016) 203:90-7. doi: 10.1016/j.ijcard.2015.10.074

55. Van De Bruaene A, Hickey EJ, Kovacs AH, Crean AM, Wald RM, Silversides $\mathrm{CK}$, et al. Phenotype, management and predictors of outcome in a large cohort of adult congenital heart disease patients with heart failure. Int J Cardiol. (2018) 252:80-7. doi: 10.1016/j.ijcard.2017.10.086

56. Eindhoven JA, van den Bosch AE, Ruys TP, Opić P, Cuypers JA, McGhie JS, et al. N-terminal pro-B-type natriuretic peptide and its relationship with cardiac function in adults with congenital heart disease. J Am Coll Cardiol. (2013) 62:1203-12. doi: 10.1016/j.jacc.2013. 07.019

57. Baggen VJ, van den Bosch AE, Eindhoven JA, Schut AW, Cuypers JA, Witsenburg $\mathrm{M}$, et al. Prognostic value of N-terminal pro-Btype natriuretic peptide, troponin- $T$, and growth-differentiation factor 15 in adult congenital heart disease. Circulation. (2017) 135:264-79. doi: 10.1161/CIRCULATIONAHA.116.023255

58. Popelová JR, Kotaška K, Tomková M, Tomek J. Usefulness of N-terminal probrain natriuretic peptide to predict mortality in adults with congenital heart disease. Am J Cardiol. (2015) 116:1425-30. doi: 10.1016/j.amjcard.2015.07.070

59. Baggen VJM, Baart SJ, van den Bosch AE, Eindhoven JA, Witsenburg M, Cuypers JA, et al. Prognostic value of serial $\mathrm{N}$-terminal pro-B-type natriuretic 
peptide measurements in adults with congenital heart disease. J Am Heart Assoc. (2018) 7:e008349. doi: 10.1161/JAHA.117.008349

60. Norozi K, Buchhorn R, Yasin A, Geyer S, Binder L, Seabrook JA, et al. Growth differentiation factor 15: an additional diagnostic tool for the risk stratification of developing heart failure in patients with operated congenital heart defects? Am Heart J. (2011) 162:131-5. doi: 10.1016/j.ahj.2011.03.036

61. Eindhoven JA, van den Bosch AE, Oemrawsingh RM, Baggen VJ, Kardys I, Cuypers JA, et al. Release of growth-differentiation factor 15 and associations with cardiac function in adult patients with congenital heart disease. Int J Cardiol. (2016) 202:246-51. doi: 10.1016/j.ijcard.2015.09.010

62. Li Y, Wang XM, Liu YL, Shi K, Yang YF, Guo YH. Plasma concentration of growth-differentiation factor-15 in children with congenital heart disease: relation ship to heart function and diagnostic value in heart failure. Zhongguo Dang Dai Er Ke Za Zhi. (2013) 15:95-8.

63. Li G, Li Y, Tan XQ, Jia P, Zhao J, Liu D, et al. Plasma growth differentiation factor-15 is a potential biomarker for pediatric pulmonary arterial hypertension associated with congenital heart disease. Pediatr Cardiol. (2017) 38:1620-6. doi: 10.1007/s00246-017-1 705-7

64. Eindhoven JA, Roos-Hesselink JW, van den Bosch AE, Kardys I, Cheng JM, Veenis JF, et al. High-sensitive troponin-T in adult congenital heart disease. Int J Cardiol. (2015) 184:405-11. doi: 10.1016/j.ijcard.2015.02.027

65. Baggen VJM, van den Bosch AE, van Kimmenade RR, Eindhoven JA, Witsenburg M, Cuypers JAAE, et al. Red cell distribution width in adults with congenital heart disease: a worldwide available and lowcost predictor of cardiovascular events. Int J Cardiol. (2018) 260:605. doi: 10.1016/j.ijcard.2018.02.118

66. Alshawabkeh L, Rajpal S, Landzberg MJ, Emani S, Ephrem G, Gray C, et al. Relationship of red cell distribution width to adverse outcomes in adults with congenital heart disease (from the Boston Adult Congenital Heart Biobank). Am J Cardiol. (2018) 122:1557-64. doi: 10.1016/j.amjcard.2018. 07.019

67. Baggen VJM, van den Bosch AE, Eindhoven JA, Menting ME, Witsenburg M, Cuypers JAAE, et al. Prognostic value of galectin-3 in adults with congenital heart disease. Heart. (2018) 104:394-400. doi: 10.1136/heartjnl-2017-312070

68. Lukasz A, Beutel G, Kümpers P, Denecke A, Westhoff-Bleck M, Schieffer $\mathrm{B}$, et al. Angiopoietin-2 in adults with congenital heart disease and heart failure. PLoS ONE. (2013) 8:e66861. doi: 10.1371/journal.pone.00 66861

69. Tutarel O, Denecke A, Bode-Böger SM, Martens-Lobenhoffer J, Lovric $\mathrm{S}$, Bauersachs J, et al. Asymmetrical dimethylarginine-more sensitive than NT-proBNP to diagnose heart failure in adults with congenital heart disease. PLoS ONE. (2012) 7:e33795. doi: 10.1371/journal.pone.00 33795
70. Opotowsky AR, Valente AM, Alshawabkeh L, Cheng S, Bradley A, Rimm $\mathrm{EB}$, et al. Prospective cohort study of C-reactive protein as a predictor of clinical events in adults with congenital heart disease: results of the Boston adult congenital heart disease biobank. Eur Heart J. (2018) 39:325361. doi: 10.1093/eurheartj/ehy362

71. Hogenhuis J, Voors AA, Jaarsma T, Hillege HL, Boomsma F, van Veldhuisen DJ. Influence of age on natriuretic peptides in patients with chronic heart failure: a comparison between ANP/NT-ANP and BNP/NT-proBNP. Eur J Heart Fail. (2005) 7:81-6. doi: 10.1016/j.ejheart.2004.03.014

72. Yap SC, Harris L, Chauhan VS, Oechslin EN, Silversides CK. Identifying high risk in adults with congenital heart disease and atrial arrhythmias. Am J Cardiol. (2011) 108:723-8. doi: 10.1016/j.amjcard.2011.04.021

73. Lin EY, Cohen HW, Bhatt AB, Stefanescu A, Dudzinski D, DeFaria Yeh D, et al. Predicting outcomes using the Heart Failure Survival Score in adults with moderate or complex congenital heart disease. Congenit Heart Dis. (2015) 10:387-95. doi: 10.1111/chd.12229

74. Stefanescu A, Macklin EA, Lin E, Dudzinski DM, Johnson J, Kennedy KF, et al. Usefulness of the Seattle Heart Failure Model to identify adults with congenital heart disease at high risk of poor outcome. Am J Cardiol. (2014) 113:865-70. doi: 10.1016/j.amjcard.2013.11.043

75. Norozi K, Wessel A, Buchhorn R, Alpers V, Arnhold JO, Zoege M, et al. Is the Ability index superior to the NYHA classification for assessing heart failure?: comparison of two classification scales in adolescents and adults with operated congenital heart defects. Clin Res Cardiol. (2007) 96:5427. doi: 10.1007/s00392-007-0530-z

Conflict of Interest: The authors declare that the research was conducted in the absence of any commercial or financial relationships that could be construed as a potential conflict of interest.

Publisher's Note: All claims expressed in this article are solely those of the authors and do not necessarily represent those of their affiliated organizations, or those of the publisher, the editors and the reviewers. Any product that may be evaluated in this article, or claim that may be made by its manufacturer, is not guaranteed or endorsed by the publisher.

Copyright (C) 2022 Leczycki, Banach, Maciejewski and Bielecka-Dabrowa. This is an open-access article distributed under the terms of the Creative Commons Attribution License (CC BY). The use, distribution or reproduction in other forums is permitted, provided the original author(s) and the copyright owner(s) are credited and that the original publication in this journal is cited, in accordance with accepted academic practice. No use, distribution or reproduction is permitted which does not comply with these terms. 